\title{
Possible association between subtypes of dry eye disease and seasonal variation
}

This article was published in the following Dove Press journal:

Clinical Ophthalmology

30 September 2017

Number of times this article has been viewed

\section{Masahiko Ayaki \\ Motoko Kawashima \\ Miki Uchino \\ Kazuo Tsubota \\ Kazuno Negishi}

Department of Ophthalmology, Keio University, Shinjuku, Tokyo, Japan
Correspondence: Masahiko Ayaki; Kazuno Negishi

Department of Ophthalmology, Keio University, 35 Shinanomachi, Shinjuku, 160-8582 Tokyo, Japan Tel/fax +8I 33705480 I

Email mayaki@olive.ocn.ne.jp; fwic7788@mb.infoweb.ne.jp
Purpose: The purpose of this study was to evaluate the influence of seasons on the signs and symptoms of dry eye disease (DED).

Methods: This is a cross-sectional, case-control study, and participants were non-DED subjects $(n=1,916$, mean age $54.4 \pm 14.4$ years $)$ and DED patients $(n=684,54.2 \pm 12.1$ years) visiting six eye clinics at various practices and locations in Japan. We evaluated the signs and symptoms of DED and the seasons with the most severe results were compared to those with the least severe results in both groups. Main outcome measures were differences in the severity of the signs and symptoms of DED between the most and least severe seasons.

Results: The majority of DED symptoms were most severe during spring and least severe in summer. Significant differences between these two seasons were found for irritation $(P=0.001)$, pain $(P=0.007)$, blurring $(P=0.000)$, and photophobia $(P=0.007)$ in the DED group. Superficial punctate keratopathy $(P=0.001)$ and tear break-up time (BUT; $P=0.000)$ results also indicated that DED was most severe in spring. In contrast, fewer patients had low Schirmer test results in spring, although this was not statistically significant $(P=0.061)$.

Conclusion: Our results demonstrated that the severity of DED is seasonal, which may explain the increase of short BUT-type DED cases observed in spring when air pollen counts are highest.

Keywords: dry eye disease, seasonality, tear break-up time, cornea, ocular surface, tear production, hay fever, air pollen, allergic conjunctivitis

\section{Introduction}

The symptoms and signs of dry eye disease (DED) may be influenced by the weather, seasons, and other environmental factors. ${ }^{1-4}$ Previous investigations have indicated that different seasons (spring, summer, and winter), cold and hot weather, wind, and sunshine may all exacerbate DED. ${ }^{1-3}$ Air pollen is a seasonal environmental factor ${ }^{3}$ that can induce allergic conjunctivitis, a problem that may be associated with DED. ${ }^{5,6}$ A national survey demonstrated a close association between the severity of hay fever and elevated air pollen counts. ${ }^{7,8}$ The highest incidence of plant pollution (mostly Cryptomeria japonica and Chamaecyparis obtusa) and aeolian dust (Kosa) ${ }^{7,8}$ also occurs in spring. DED-related tests may also be climate dependent, with one study reporting that the results of DED tests used to assess ocular surface health and tear stability varied depending on the climate. ${ }^{2}$

Many studies have used questionnaires or coding databases to evaluate the effects different seasons have on DED; however, none have objectively assessed ophthalmic patients who have been recruited over the four seasons. The aim of the present study was to evaluate the effects of each season on the signs and symptoms of DED. Japan has four distinct seasons during which the temperature, humidity, and daylight time markedly 
varies. It is hot and humid in summer and cold and dry in winter. Between 1981 and 2010, the average temperature and humidity in the Tokyo area ranged from $5.2^{\circ} \mathrm{C}$ and $52 \%$ in winter to $25.0^{\circ} \mathrm{C}$ and $77 \%$ in summer, respectively. ${ }^{9} \mathrm{We}$ analyzed corneal findings, tear film function, and DED-related symptoms over 1 year and herein report the differences in the results obtained for each season. Finally, we attempted to demonstrate that DED subtypes could be associated with particular seasons. For example, short break-up time (BUT)-type DED may be more frequent in spring when allergen counts are much higher, and aqueous tear deficiency-type DED may be more frequent in winter when conditions are dry.

\section{Methods}

\section{Study participants and institutional review board approval}

This cross-sectional, case-control study was conducted in Komoro Kosei General Hospital (Nagano, Japan), Shinseikai Toyama Hospital (Toyama, Japan), Tsukuba Central Hospital (Ibaraki, Japan), Jiyugaoka Ekimae Eye Clinic (Tokyo, Japan), Todoroki Eye Clinic (Tokyo, Japan), and Takahashi-Hisashi Eye Clinic (Akita, Japan). The Institutional Review Board and Ethics Committee of Keio University School of Medicine, Komoro Kosei General Hospital, Tsukuba Central Hospital, and Jiyugaoka Ekimae Eye Clinic approved this study, and the methods were carried out in accordance with the Declaration of Helsinki. These hospitals provided ethical approval for the remaining eye clinics, which were classified as collaborators in the ethical documents approved by the hospitals' ethics committees. Informed consent was obtained from all participants.

\section{Inclusion and exclusion criteria}

The present study recruited consecutive patients aged $\geq 20$ years with best corrected visual acuity equal to or better than 20/25 in both the eyes from participating clinics and hospitals between April 2015 and April 2016. Subjects with any acute diseases, cataract, fundus pathology including macular diseases, contact lens wear, history of refractive surgery, punctal occlusion, and punctal plug insertion, all of which may lead to visual and non-visual symptoms, were excluded from the study. To exclude vision disorders that are possibly related to DED symptoms, ${ }^{10}$ patients were excluded if they had severe glaucoma (mean deviation $<-12 \mathrm{~dB}$ in either eye), clinically significant cataracts, or bilateral visual impairment ( $<20 / 30$ in both eyes).

\section{Ophthalmological examinations}

All outpatients were examined by a board-certified ophthalmologist specializing in cornea services. BUT was measured using a wetted fluorescein filter paper (Ayumi Pharmaceutical Co Ltd, Tokyo, Japan) applied at the lower lid margin. Subjects were instructed to blink three times to ensure adequate mixing of the fluorescein dye with the tear film. The time interval between the third blink and appearance of the first dark spot in the cornea was measured three consecutive times using a stopwatch. The means of the three measurements were regarded as the BUT measurements in this study. The ocular surface was divided into three sections: the nasal conjunctiva, the cornea, and the temporal conjunctiva. Each surface was graded on a scale of $0-3$ for severity, and the overall epithelial damage was scored on a scale of 0-9. The Schirmer test was performed without topical anesthesia. Strips of filter paper (Whatman No 41; Showa Yakuhin Kako Co Ltd, Tokyo, Japan) were placed at the outer third of the temporal lower conjunctival fornix for 5 minutes, with the subject spontaneously blinking. The strips were then removed, and the length in millimeters of the filter paper wetted by the spontaneous blinks was recorded. The maximum blinking interval (MBI) was also used to detect and quantify DED as differences in the mean MBI have been reported between non-DED ( $8.9 \pm 4.0$ seconds) and DED patients (4.2 \pm 2.4 seconds). ${ }^{11}$ The MBI was expressed as the number of seconds the eyes could stay open without blinking.

We used prescription-based classification for analysis in the present study. Patients with no history of treatment and no requirement of DED eyedrop at examination were classified as non-DED. Depending on the severity of DED, patients were prescribed topical medications. We considered DED to be mild if the symptoms and signs could be controlled by hyaluronate alone. Patients with symptoms of dryness and ocular pain that could not be controlled by hyaluronate, and/or with DED signs including persistent epithelial defects and conjunctival injection, were prescribed additional medications and classified as having severe DED. For new patients, participating ophthalmologists determined the prescription of eyedrops mostly by the severity of symptoms, especially in cases with mild signs. Eventually patients with severe DED had steroid and/or mucin secretagogue eyedrops for their severe symptoms. As indicated in previous studies, a prescription-based classification rather than one based on the Japanese Dry Eye Society guidelines ${ }^{12}$ was relevant for the statistical analyses undertaken in this study. ${ }^{13,14}$ The criteria of the Japanese Dry Eye Society classifies DED into definite DED (DDED), probable DED (PDED), and nonDED according to the presence of DE symptoms, tear abnormalities (Schirmer test $\leq 5 \mathrm{~mm}$ or BUT $\leq 5$ seconds), and superficial punctate keratopathy (SPK; staining score $\geq 3$ ). Cases were classified as DDED if all three signs were present, 
as PDED if two signs were present, and as non-DED if only one sign or no signs were present.

\section{Patient interviews for DED-related symptoms}

Patients were asked questions to determine the presence or absence of six common DED-related symptoms, namely dryness, irritation, and pain as non-visual symptoms and, eye fatigue, blurring, and photophobia as visual symptoms. These questions were selected from items in the Dry Eye Questionnaire Score ${ }^{15}$ and were based on the six most prevalent symptoms of DED patients who had visited the Dry Eye Clinic in the Department of Ophthalmology at Keio University Hospital in 2014. We classified eye fatigue, blurring, and photophobia as visual symptoms and dryness, irritation, and pain as non-visual symptoms.

\section{Statistical analysis}

We first classified the patients into non-DED and DED groups according to prescriptions received for DED and then analyzed each participant's symptoms and signs. The seasons were classified as follows: spring from March to May, summer from June to August, fall from September to November, and winter from December to February. The effects of each season on the symptoms and signs of DED were compared in the following way. First, the percentage of participants presenting with DED symptoms and abnormal test results were determined for every season. Schirmer test and tear BUT test results from the right eye only were used for analysis. Second, from this, we determined the severity of each sign and symptom according to the season. We then compared the season with the least severe results to that with the most severe results for each sign and symptom and used the chi-square test to determine if the differences between these seasons were significant. Data are presented as the mean \pm standard deviation (SD) or as percentages where appropriate. All analyses were performed using StatFlex (Atech, Osaka, Japan), with $P<0.05$ considered significant.

\section{Results \\ Study participants}

A total of 2,600 outpatients participated in this study, and $684(26.3 \%)$ were diagnosed with DED using a prescriptionbased classification (Table 1). The mean age of participants in the non-DED group was $54.4 \pm 14.4$ years and $42.7 \%$ were male. The mean age of participants in the DED group was $56.1 \pm 18.1$ years and $19.3 \%$ were male. More women than men were diagnosed with DED in this study $(P=0.000$, chi-square test), and patients in the DED group were older than those in the non-DED group ( $P=0.047$, Mann-Whitney $U$ test). A significant seasonal difference was observed for intra-ocular pressure only ( $P=0.002$, Kruskal-Wallis test). Most of the participants $(62 \%)$ were recruited from three eye clinics in the Tokyo metropolitan area and two eye clinics in the mid-Japan area $(35 \%)$. The remaining participants $(3 \%)$ were recruited from an eye clinic in the northern area. When the types of eye clinic that participants were recruited from were compared, we found that $48.9 \%$ were recruited from general hospitals and eye hospitals and $51.1 \%$ from vision care clinics.

\section{Seasonal variation of DED signs and symptoms}

Table 2 and Figures 1 and 2 show the seasonal variation of DED symptoms and signs in the two patient groups. We also

Table I Patient characteristics

\begin{tabular}{|c|c|c|c|c|c|c|c|}
\hline \multirow{2}{*}{$\frac{\text { Diagnostic group }}{\text { Recruitment season }}$} & \multirow[t]{2}{*}{ Non-DEDA } & \multicolumn{5}{|l|}{ DED ${ }^{A}$} & \multirow[t]{2}{*}{$P$-value* } \\
\hline & & Spring & Summer & Fall & Winter & Total & \\
\hline Number of patients (n) & 1,916 & 143 & 143 & 229 & 169 & 684 & \\
\hline$\%$ male & 42.7 & 18.2 & 21.7 & 16.6 & 21.9 & 19.3 & 0.697 \\
\hline Age $\left(\right.$ years) ${ }^{B}$ & $54.4 \pm 14.4$ & $54.4 \pm 16.5$ & $56.7 \pm 15.5$ & $57.6 \pm 16.8$ & $54.9 \pm 15.1$ & $56.1 \pm 18.1$ & 0.219 \\
\hline Median & 56 & 56 & 58 & 62 & 55 & 57 & \\
\hline Range & 20-92 & $20-89$ & $21-88$ & $20-91$ & $20-94$ & $20-94$ & \\
\hline High myopia ( $\leq-6.00$ D) (\%) & 15.9 & 14.4 & 9.6 & 14.6 & 17.0 & 14.0 & 0.532 \\
\hline Bilateral pseudophakia (\%) & 7.7 & 6.3 & 2.8 & 8.2 & 13.2 & 7.7 & 0.056 \\
\hline Intraocular pressure $(\mathrm{mmHg})^{B}$ & $|4.0 \pm 3|$. & $14.5 \pm 3.0$ & $14.4 \pm 3.0$ & $14.1 \pm 2.9$ & $15.4 \pm 3.9$ & $14.6 \pm 3.2$ & $0.002 *$ \\
\hline Topical glaucoma medication (\%) & 7.7 & 7.0 & 5.7 & 8.8 & 13.9 & 8.9 & 0.200 \\
\hline \multicolumn{8}{|l|}{ Topical DED medication (\%) } \\
\hline Hyaluronate & 0 & 51.7 & 49.7 & 50.4 & 64.6 & 53.5 & 0.107 \\
\hline Mucin secretagogue & 0 & 32.9 & 33.6 & 39.4 & 25.7 & 33.9 & 0.164 \\
\hline Steroid & 0 & 14.8 & 16.8 & 10.2 & 9.7 & 12.6 & 0.245 \\
\hline
\end{tabular}

Notes: ${ }^{A}$ Classified as DED or non-DED according to the prescription. ${ }^{B}$ Mean \pm SD. ${ }^{*} P<0.05$, Kruskal-Wallis test or chi-square test as appropriate for comparing the 4 seasons.

Abbreviation: DED, dry eye disease. 
Table 2 Seasonal variations in DED signs and symptoms

\begin{tabular}{|c|c|c|c|c|c|c|c|c|}
\hline \multirow[t]{2}{*}{ Recruitment season } & \multirow[t]{2}{*}{ Non-DED ${ }^{A}$} & \multicolumn{4}{|l|}{ DED $^{A}$} & \multicolumn{3}{|c|}{$\begin{array}{l}\text { Seasonal severity of DED } \\
\text { symptoms and signs }\end{array}$} \\
\hline & & Spring & Summer & Fall & Winter & $\begin{array}{l}\text { Least } \\
\text { severe }\end{array}$ & $\begin{array}{l}\text { Most } \\
\text { severe }\end{array}$ & $P$-value* \\
\hline PDED and DDED & - & $71.3(102 / 143)$ & $51.0(73 / \mid 43)$ & $66.1(151 / 229)$ & $70.8(120 / 169)$ & Summer & Spring & 0.000 \\
\hline DDED & - & $11.2(16 / 143)$ & $9.2(13 / 143)$ & $12.8(29 / 229)$ & $9.4(16 / 169)$ & Summer & Fall & 0.104 \\
\hline \multicolumn{9}{|l|}{ Signs } \\
\hline SPK (staining score $\geq 3$ ) & $6.1(117 / 1,916)$ & $29.4(42 / / 43)$ & $13.3(19 / 143)$ & I $5.7(36 / 229)$ & $22.2(36 / 169)$ & Summer & Spring & 0.001 \\
\hline Schirmer test $(\leq 5 \mathrm{~mm})$ & $19.0(23 / 122)$ & $17.1(6 / 35)$ & $27.9(17 / 61)$ & $21.4(8 / 39)$ & $41.2(8 / 20)$ & Spring & Winter & 0.061 \\
\hline $\mathrm{BUT}(\leq 5 \mathrm{~s})$ & $42.6(8 / 2 / 1,907)$ & $73.9(105 / 142)$ & $52.4(75 / \mid 43)$ & $58.3(134 / 229)$ & $63.6(105 / 168)$ & Summer & Spring & 0.000 \\
\hline $\mathrm{MBI}(\leq 9 \mathrm{~s})$ & $25.7(488 / 1,900)$ & $30.0(39 / 130)$ & $41.5(59 / 142)$ & $35.4(84 / 229)$ & $35.4(57 / 169)$ & Spring & Summer & 0.013 \\
\hline \multicolumn{9}{|l|}{ Symptoms } \\
\hline Dryness & $21.8(4|7 / I, 9| 5)$ & $42.0(60 / 143)$ & $51.0(73 / \mid 43)$ & $54.3(121 / 223)$ & $52.8(89 / 169)$ & Summer & Fall & 0.113 \\
\hline Irritation & |3.8 (264/I,9| I) & $37.1(53 / 143)$ & $20.3(28 / 138)$ & $30.4(70 / 229)$ & $24.3(4|/| 69)$ & Summer & Spring & 0.001 \\
\hline Pain & $4.6(50 / 1,911)$ & $12.6(18 / 143)$ & $7.1(10 / 141)$ & $15.4(35 / 229)$ & $12.5(21 / 169)$ & Summer & Fall & 0.007 \\
\hline Fatigue & $28.1(538 / 1,915)$ & $47.6(68 / 143)$ & $44.1(63 / \mid 43)$ & $43.5(98 / 225)$ & $54.2(90 / 166)$ & Fall & Winter & 0.105 \\
\hline Blurring & $14.6(279 / 1,9 \mid 1)$ & $38.5(55 / 143)$ & $7.2(10 / 141)$ & $17.0(37 / 218)$ & $28.5(47 / 165)$ & Summer & Spring & 0.000 \\
\hline Photophobia & $13.9(266 / 1,9 \mid 1)$ & $25.2(36 / 143)$ & $13.1(18 / 137)$ & $21.3(48 / 225)$ & $23.6(40 / 169)$ & Summer & Spring & 0.007 \\
\hline
\end{tabular}

Notes: APrescription-based classification. Data are presented as percentages, with $n$ values (number of positive subjects/number of examined subjects) in parentheses. *Chisquare test.

Abbreviations: BUT, tear break-up time; DDED, definite DED; DED, dry eye disease; MBI, maximum blinking interval; PDED, probable DED; SPK, superficial punctuate keratitis.
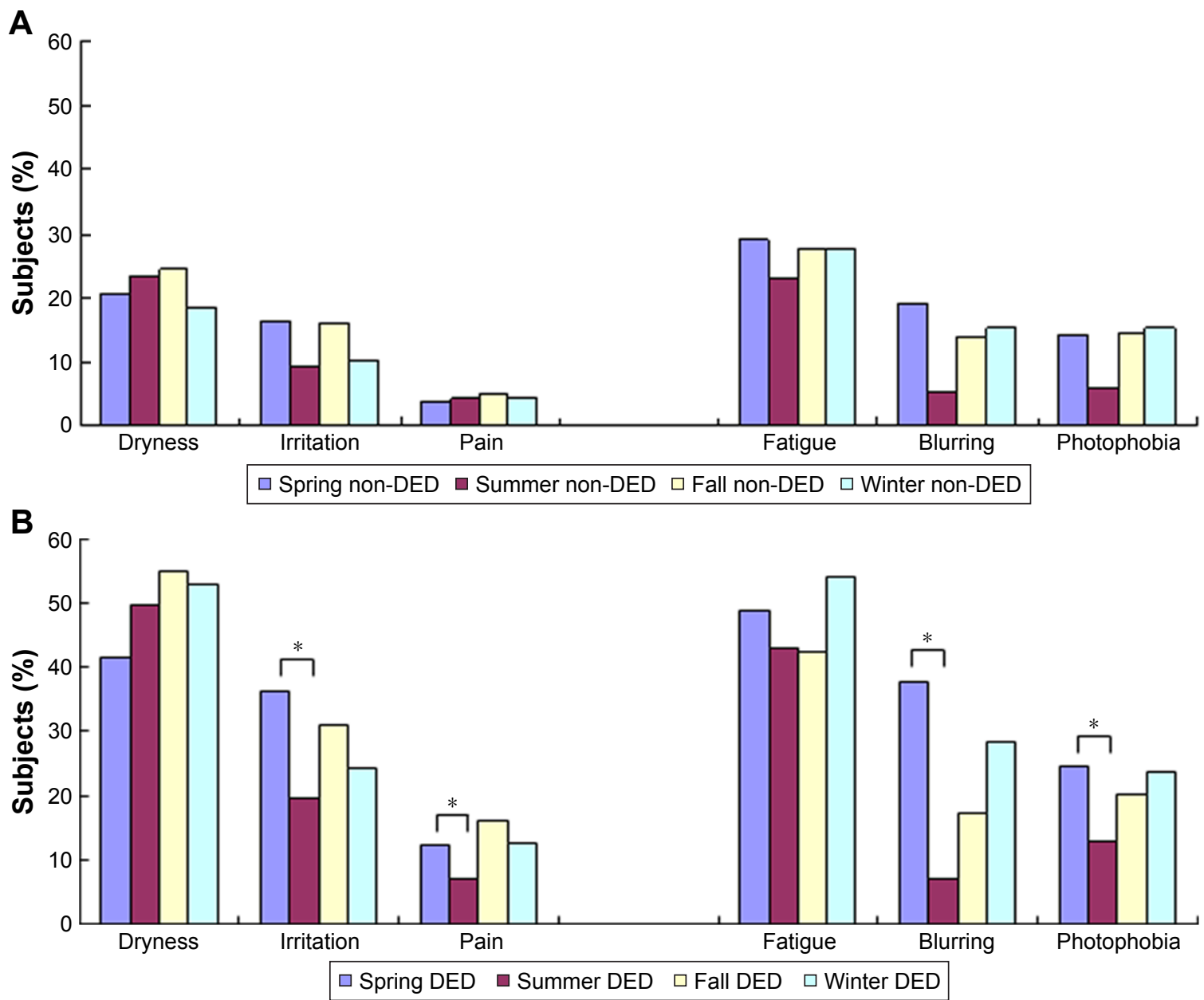

Figure I Presence of DED-related symptoms in (A) non-DED and (B) DED patients. Seasonal variation was observed for irritation, pain, blurring, and photophobia in DED patients, with symptoms being most severe in spring. Seasonal variation was also observed in the non-DED subjects, with symptoms being least severe in summer. There was no significant variation in the severity of symptoms between summer, fall, and winter in the non-DED subjects. ${ }^{*} P<0.05$ when the season with the most severe symptoms was compared to the season with the least severe symptoms (chi-square test).

Abbreviation: DED, dry eye disease. 
A

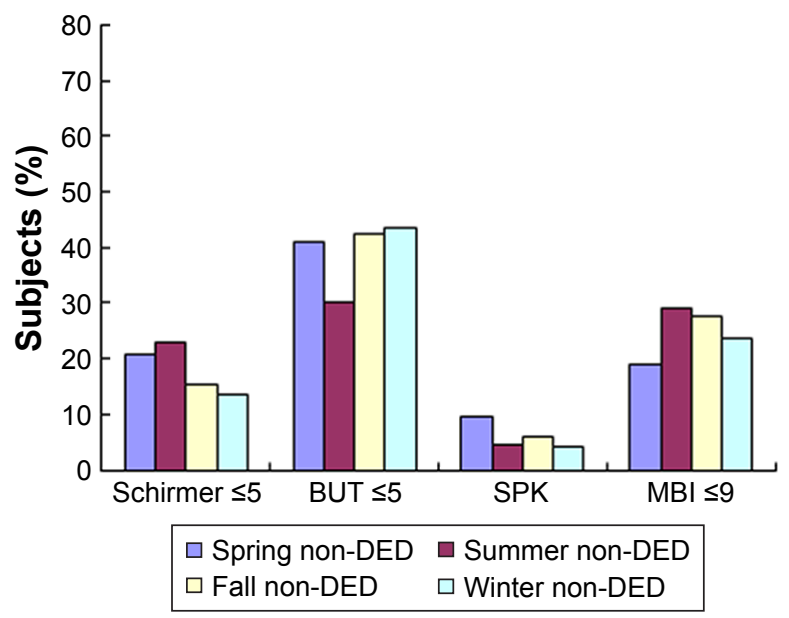

B

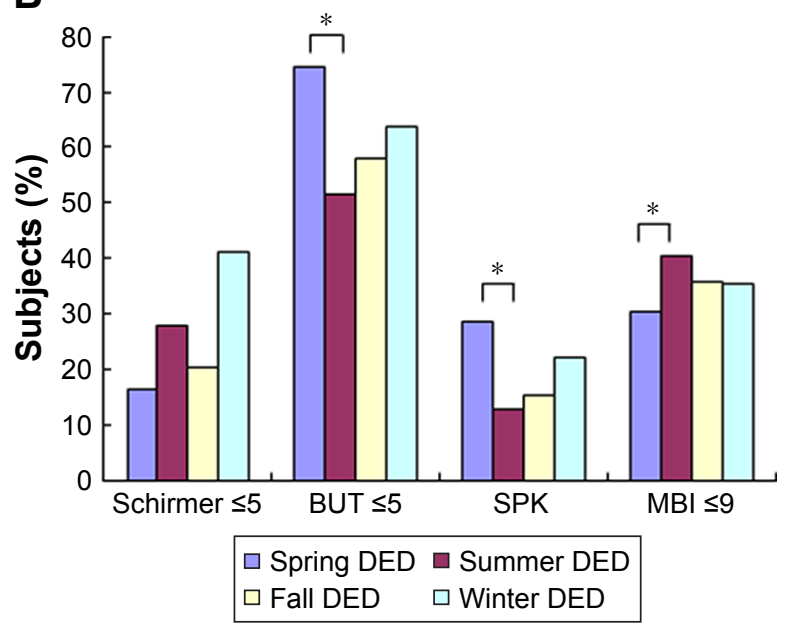

Figure 2 Presence of DED-related signs in (A) non-DED and (B) DED patients. Seasonal variation was observed in BUT and SPK in the DED patients. Seasonal variation in all signs except for the Schirmer test was observed in the non-DED subjects. $* P<0.05$ when the season with the most severe symptoms was compared to the season with the least severe symptoms (chi-square test).

Abbreviations: BUT, tear break-up time; DED, dry eye disease; MBI, maximum blinking interval; SPK, superficial punctuate keratitis.

compared the season in which each sign and symptom was most severe with the season in which they were least severe (Table 2; Figures 1 and 2). The majority of symptoms were most severe in spring and least severe in summer, and when these seasons were compared in the DED group, significant results were found for irritation $(P=0.001)$, pain $(P=0.007)$, blurring $(P=0.000)$, and photophobia $(P=0.007$, Figure $1 \mathrm{~B})$, as well as $\operatorname{SPK}(P=0.001)$ and $\operatorname{BUT}(P=0.000$, Figure $2 \mathrm{~B})$. The overall pattern of seasonal severity was similar for symptoms of pain, fatigue, and photophobia (Figure 1B). In contrast, the Schirmer test values were highest in spring and lowest in winter; that is, tear production was greatest in spring and lowest in winter (Figure 2B). Seasonal effects were also observed in the non-DED group, with most symptoms and signs being considerably less severe in summer (Figures 1A and 2A). However, the differences in severity between summer, winter, and fall were not as large as those observed in the DED patients.

\section{Discussion}

This study demonstrated that many of the signs and symptoms of DED are associated with each season. DED symptoms and signs were generally most severe in spring and least severe in summer for DED patients, indicating that the high temperatures and high humidity in summer may be ideal for DED sufferers. Blurring, photophobia, irritation, BUT, and SPK were most severe during spring; however, there was no significant variation in the severity of these DED signs and symptoms between summer, fall, and winter. This suggests that something may trigger an increase in the severity of DED symptoms and signs in spring such as air-borne pollens.
As elevated air pollen counts are directly associated with the severity of hay fever, ${ }^{7,8}$ seasonal allergens are expected to be an exacerbating factor for DED. In keeping with our results, the Japan Meteorological Agency reported that the pollen counts in Japan were highest from the beginning of March to the end of April in 2015 and 2016. ${ }^{7,8}$ In contrast, we found that the number of participants with a low Schirmer test result was lowest in spring. This suggests that tear production may increase in spring as a scavenging response to an increase in seasonal allergens, demonstrating another link between DED and seasonal allergens. Based on our results, which showed increases in the occurrence of short BUT-type DED in spring and aqueous tear deficiency-type DED in winter, DED subtypes may be subject to seasonal variation. According to a recent review from Asia Dry Eye Society, ${ }^{16}$ BUT and symptoms were recognized as major diagnostic criteria and the importance of visual symptoms was emphasized as a result of unstable tear film. Our results clearly corresponded to this new criterion since seasonal variation of BUT was quite similar to that of visual symptoms including fatigue, blurring, and photophobia.

A number of risk factors and confounding factors can affect the clinical presentation of DED. ${ }^{17-26}$ The severity of DED may be affected by age-dependent tear secretion ${ }^{17}$ diurnal variation of tear secretion and visual function, ${ }^{18,19}$ neural regulation, ${ }^{20,21}$ sleep deprivation, ${ }^{22}$ blue light exposure, ${ }^{23,24}$ eye closure, ${ }^{25}$ and display watching. ${ }^{26}$ In addition, general parameters including smoking, age, sex, LASIK, connective tissue disease, and medications including anti-cholinergics ${ }^{27-29}$ may also affect the severity of DED. Indeed, our results showed that women were more likely to have DED than men, which is 
consistent with previous reports. ${ }^{30-32}$ The effects of hormones and hormone replacement therapy on DED and climacteric symptoms ${ }^{33,34}$ have been investigated; however, the results are inconclusive. DED affects happiness, ${ }^{35}$ quality of life, ${ }^{36,37}$ and sleep. ${ }^{14,38-41}$ It is also closely associated with depression. ${ }^{41}$ Due to its high prevalence and these considerable impacts on health and productivity, ${ }^{42}$ a better understanding of DED is critical for the general population and health professionals.

Various diagnostic criteria, different seasons, and differing clinic practices may greatly contribute to the statistical variations observed in clinical DED research. The present study has strived to be well designed and has analyzed a sufficient sample size. Patients from both hospitals and vision care clinics were recruited over a 1-year period by direct interviews and physicians' examinations. We endeavored to maintain the homogeneity of the data set even though patients were recruited from various ophthalmic practices and locations by ensuring that the same criteria were used by all participating institutes. We found that the prevalence and severity of DED was greater in patients who visited vision care clinics in the Tokyo metropolitan area compared with those who visited hospitals in other regions of Japan (data not shown). This finding is consistent with the results of another investigation..$^{30}$ It is possible that this is because individuals with undiagnosed DED find it difficult to visit hospitals since most hospital services require reservations or a referral letter and have limited registration hours. In contrast, vision care clinics are much more accessible. We are currently working to resolve this topic.

\section{Limitations}

We would like to emphasize several limitations of our study. First, we did not exclude glaucoma, early cataract, or pseudophakic patients, even though these comorbidities may affect the symptoms and signs of DED. Second, DED itself is a multifactorial disease with many possible confounding factors that may potentially be affected by seasonal variations, including systemic and psychiatric comorbidities, medications, and ocular complications. We did not check the participants' detailed medical histories due to time and space limitations in the participating institutions. Third, the self-reported symptoms of DED are subject to reporting bias, as there is variation in how different individuals experience symptoms of pain, irritation, and sensitivity. The results of this study should be confirmed further using a comprehensive DED classification such as the one proposed by the 2007 Dry Eye Workshop, ${ }^{43}$ although our results were consistent with diagnostic criteria of Asia Dry Eye Society. ${ }^{16}$

\section{Conclusion}

In conclusion, the present results indicate that patients with DED may suffer most seriously in spring. Our findings also demonstrate that DED subtypes can be subject to seasonal variation. We found an increase in cases of short BUT-type DED in spring, possibly due to elevated air pollen counts.

\section{Acknowledgments}

The authors thank Dr Yoshihiro Hashimoto, Dr Naoko Tachi, Dr Kazuo Takei, Dr Yuho Ichikawa, and Dr Naohisa Nezu for help with data collection, and Dr Takayuki Abe for help with statistical analyses. The authors acknowledge the assistance of Inter-Biotech with the English language editing of this manuscript.

\section{Disclosure}

The authors report no conflicts of interest in this work.

\section{References}

1. van Setten G, Labetoulle M, Baudouin C, Rolando M. Evidence of seasonality and effects of psychometry in dry eye disease. Acta Ophthalmol. 2016;94(5):499-506.

2. Tesón M, López-Miguel A, Neves H, et al. Influence of climate on clinical diagnostic dry eye tests: pilot study. Optom Vis Sci. 2015;92(9): e284-e289.

3. Kumar N, Feuer W, Lanza NL, Galor A. Seasonal variation in dry eye. Ophthalmology. 2015;22:1727-1729.

4. López-Miguel A, Tesón M, Martín-Montañez V, et al. Dry eye exacerbation in patients exposed to desiccating stress under controlled environmental conditions. Am J Ophthalmol. 2014;57:788-798.

5. Toda I, Shimazaki J, Tsubota K. Dry eye with only decreased tear break-up time is sometimes associated with allergic conjunctivitis. Ophthalmology. 1995;102:302-309.

6. Fujishima H, Toda I, Shimazaki J, Tsubota K. Allergic conjunctivitis and dry eye. Br J Ophthalmol. 1996;80:994-997.

7. Weathernews Inc. [Seasonal air pollen update at Jun 16, 2015]. Available at: https://jp.weathernews.com/news/5817/. Accessed September 21, 2017. Japanese.

8. Japan Meteorological Agency. Long-term Trends of Aeolian Dust. Available at: http://www.data.jma.go.jp/gmd/env/kosahp/en/kosa shindan_e.html. Accessed September 21, 2017.

9. Japan Meteorological Agency. [Average humidity and temperature (1981-2010)]. Available at: http://www.data.jma.go.jp/obd/stats/etrn/ view $/$ nml_sfc_ym.php?prec_no $=44 \&$ block_no $=47662 \&$ year $=\&$ mont $\mathrm{h}=\&$ day $=\& v i e w=$. Accessed September 21, 2017. Japanese.

10. Toda I, Fujishima H, Tsubota K. Ocular fatigue is the major symptom of dry eye. Acta Ophthalmol (Copenh). 1993;71:347-352.

11. Tsubota K, Hata S, Okusawa Y, Egami F, Ohtsuki T, Nakamori K. Quantitative videographic analysis of blinking in normal subjects and patients with dry eye. Arch Ophthalmol. 1996;114:715-720.

12. Uchino Y, Uchino M, Dogru M, et al. Changes in dry eye diagnostic status following implementation of revised Japanese dry eye diagnostic criteria. Jpn J Ophthalmol. 2012;56(1):8-13.

13. Miyake K, Yokoi N. Influence on ocular surface after cataract surgery and effect of topical diquafosol on postoperative dry eye: a multicenter prospective randomized study. Clin Ophthalmol. 2017;11: $529-540$. 
14. Ayaki M, Kawashima M, Kishimoto T, Mimura M, Negishi K, Tsubota K. Sleep and mood disorders in dry eye disease and allied ocular surface diseases. Sci Rep. 2016;6:22480.

15. Sakane Y, Yamaguchi M, Yokoi N, et al. Development and validation of the dry eye-related quality-of-life score questionnaire. JAMA Ophthalmol. 2013;131:1331-1338.

16. Tsubota K, Yokoi N, Shimazaki J, et al. New perspectives on dry eye definition and diagnosis: a consensus report by the asia dry eye society. Ocul Surf. 2017;15:65-76.

17. Arita R, Itoh $\mathrm{K}$, Inoue $\mathrm{K}$, Amano S. Noncontact infrared meibography to document age-related changes of the meibomian glands in a normal population. Ophthalmology. 2008;115:911-915.

18. Srinivasan S, Chan C, Jones L. Apparent time-dependent differences in inferior tear meniscus height in human subjects with mild dry eye symptoms. Clin Exp Optom. 2007;90:345-350.

19. Walker PM, Lane KJ, Ousler GW 3rd, Abelson MB. Diurnal variation of visual function and the signs and symptoms of dry eye. Cornea. 2010; 29:607-612.

20. Stapleton F, Marfurt C, Golebiowski B, et al. The TFOS International Workshop on Contact Lens Discomfort: report of the subcommittee on neurobiology. Invest Ophthalmol Vis Sci. 2013;54(11):TFOS71-TFOS97.

21. Dartt DA. Neural regulation of lacrimal gland secretory processes relevance in dry eye diseases. Prog Retin Eye Res. 2009;28:155-177.

22. Lee YB, Koh JW, Hyon JY, Wee WR, Kim JJ, Shin YJ. Sleep deprivation reduces tear secretion and impairs the tear film. Invest Ophthalmol Vis Sci. 2014;55:3525-3531.

23. Kaido M, Toda I, Oobayashi T, Kawashima M, Katada Y, Tsubota K. Reducing short-wavelength blue light in dry eye patients with unstable tear film improves performance on tests of visual acuity. PLoS One 2016;11:e0152936.

24. Niwano Y, Kanno T, Iwasawa A, Ayaki M. Blue light injures corneal epithelial cells in the mitotic phase in vitro. Br J Ophthalmol. 2014;98: 990-992.

25. Sack RA, Beaton A, Sathe S, Morris C, Willcox M, Bogart B. Towards a closed eye model of the pre-ocular tear layer. Prog Retin Eye Res. 2000;19:649-668.

26. Tsubota K, Nakamori K. Dry eyes and video display terminals. N Engl J Med. 1993;328:584.

27. Remick RA. Anticholinergic side effects of tricyclic antidepressants and their management. Prog Neuropsychopharmacol Biol Psychiatry. 1998;12:225-231.

28. Koçer E, Koçer A, Özsütçü M, Dursun AE, Krpnar İ. Dry eye related to commonly used new antidepressants. J Clin Psychopharmacol. 2015;35:411-413.

29. Mrugacz M, Ostrowska L, Łazarczyk-Kirejczyk J, et al. Dry eye disease in patients treated with antidepressants. Klin Oczna. 2013;115: 111-114. Polish
30. Hikichi T, Yoshida A, Fukui Y, et al. Prevalence of dry eye in Japanese eye centers. Graefe's Arch Clin Exp Ophthalmol. 1995;233:555-558.

31. Uchino M, Nishiwaki Y, Michikawa T, et al. Prevalence and risk factors of dry eye disease in Japan: Koumi study. Ophthalmology. 2011;118: 2361-2367.

32. Schaumberg DA, Uchino M, Christen WG, Semba RD, Buring JE, Li JZ. Patient reported differences in dry eye disease between men and women: impact, management, and patient satisfaction. PLoS One. 2013;8: e76121.

33. Sullivan DA, Sullivan BD, Evans JE, et al. Androgen deficiency, Meibomian gland dysfunction, and evaporative dry eye. Ann N Y Acad Sci. 2002;966:211-222.

34. Feng Y, Feng G, Peng S, Li H. The effect of hormone replacement therapy on dry eye syndrome evaluated with Schirmer test and break-up time. J Ophthalmol. 2015;2015:420302.

35. Kawashima M, Uchino M, Yokoi N, et al. Associations between subjective happiness and dry eye disease: a new perspective from the Osaka Study. PLoS One. 2015;10:e0123299.

36. Le, Q, Zhou X, Ge L, Wu L, Hong J, Xu J. Impact of dry eye syndrome on vision-related quality of life in a non-clinic-based general population. BMC Ophthalmol. 2012;12:22.

37. Miljanović B, Dana R, Sullivan DA, Schaumberg DA. Impact of dry eye syndrome on vision-related quality of life. Am J Ophthalmol. 2007;143: 409-415.

38. Ayaki M, Toda I, Tachi N, Negishi K, Tsubota K. Preliminary report of improved sleep quality in patients with dry eye disease after initiation of topical therapy. Neuropsychiatr Dis Treat. 2016;12:329-337.

39. Lee W, Lim SS, Won JU, et al. The association between sleep duration and dry eye syndrome among Korean adults. Sleep Med. 2015; 16:1327-1331.

40. Galor A, Seiden BE, Park JJ, et al. The association of dry eye symptom severity and comorbid insomnia in US veterans. Eye Contact Lens. Epub 2017 Jan 6.

41. Galor A, Feuer W, Lee DJ, et al. Depression, post-traumatic stress disorder, and dry eye syndrome: a study utilizing the national United States Veterans Affairs administrative database. Am JOphthalmol.2012; 154:340-346.

42. Uchino M, Uchino Y, Dogru M, et al. Dry eye disease and work productivity loss in visual display users: the Osaka study. Am J Ophthalmol. 2014;157:294-300.

43. Subcommittee of the International Dry Eye WorkShop. The definition and classification of dry eye disease: report of the Definition and Classification Subcommittee of the International Dry Eye WorkShop. Ocul Surf. 2007;5:75-92.
Clinical Ophthalmology

\section{Publish your work in this journal}

Clinical Ophthalmology is an international, peer-reviewed journal covering all subspecialties within ophthalmology. Key topics include: Optometry; Visual science; Pharmacology and drug therapy in eye diseases; Basic Sciences; Primary and Secondary eye care; Patient Safety and Quality of Care Improvements. This journal is indexed on Submit your manuscript here: http://www.dovepress.com/clinical-ophthalmology-journa

\section{Dovepress}

PubMed Central and CAS, and is the official journal of The Society of Clinical Ophthalmology (SCO). The manuscript management system is completely online and includes a very quick and fair peer-review system, which is all easy to use. Visit http://www.dovepress.com/ testimonials.php to read real quotes from published authors. 